We doubt if this country can bear the cost or effort required to screen all women on a yearly basis. Resources would be better employed in the limited extension of screening facilities and the planning of controlled studies to answer some of these questions.

\section{(4) Risks from $X$-irradiation}

The risks from repeated mammography are uncertain. We are doubtful of the evidence suggesting that a dose of 2 rads to the breast contributes a significant risk of breast cancer ${ }^{6}$ but accept that frequently repeated exposures may be harmful. Programmes of screening must include accurate assessment of dosimetry and of the long-term risk. While the study reported from the Manchester screening clinic has indicated that adequate mammography can be carried out with a total surface dose of less than $0.2 \mathrm{rad}$ to the breast ${ }^{7}$ there is a need for more detailed investigation of technical methods which do not utilize $x$-irradiation.

\section{(5) Associated Services}

The New York study indicated that cancers detected by mammography alone have an uncommonly good prognosis. Reliable methods for sampling areas of the breast which contain only mammographic abnormalities must be established. Unless valuable information is to be lost, screening clinics must be linked with expert diagnostic and biopsy services specifically designed for the management of breast disease.

Standardization of the histology of breast biopsy specimens is urgently needed, and a panel of pathologists should be set up to advise screening clinics. It is particularly important to define the relationship of mammographic microcalcifications and histologically proved benign abnormalities to the risk of the subsequent development of invasive cancer.

\section{(6) Future Aims}

Too many women first attend hospital clinics in Britain with locally advanced or even metastatic breast cancer. Inquiry into the reasons and the development of methods to encourage all women to seek early treatment could have a profound effect in reducing the mortality from the disease; so also could the development of well organized services for the diagnosis and management of breast cancer in our hospitals. We believe that encouragement should be given to those willing to devote time and energy to this purpose. Rationally, these two considerations must have at least equal priority to a national screening service.

\section{(7) Selection of Women at Risk}

When taking into account the current state of resources, the theoretical risks from radiation, and the poor attendance rate of women offered routine screening, ${ }^{8}$ consideration should be given to concentrating programmes of screening on women at risk. Some factors associated with an increased risk of breast cancer have already been definedfor example, early menarche, late first pregnancy, family history, and abnormalities of steroid excretion. ${ }^{910}$ More basic research is required, however, before these and other factors can be used to select those women for whom regular screening will prove most effective. It is important also to determine whether a woman thought not to be at risk could be adequately screened by a single examination at a defined age.

\section{Conclusions}

In our opinion there is insufficient evidence concerning its effectiveness to justify the initiation of a national programme of breast screening. As the existing programmes will not provide enough data to answer questions raised by the New York study there should now be limited extension of existing experimental services for breast screening in centres where back-up facilities for the diagnosis and management of breast cancer are well developed. We are encouraged that the Minister of State for Health has made a step in the right direction by promoting, with the Medical Research Council, working groups to advise on some of these questions. We stress, however, that useful and valid information will be obtained only if a definite effort is made to co-ordinate the research programmes of individuai screening clinics.

\section{References}

${ }^{1}$ Minister of State for Health, The Times, 1975, 29 April, p. 8.

2 Strax, P., et al., Cancer, 1967, 20, 2184.

3 Shapiro, S., Bulletin of the New York Academy of Medicine, 1975, 51, in press.

4 Shapiro, S., personal communication.

${ }^{5}$ Knox, G., in Probes for Health. London, Nuffield Provincial Hospitals Trust. In press.

${ }^{6}$ Mole, R. H., Proceedings of M.R.C. Conference on Breast Cancer, July 1974.

${ }^{7}$ Gleave, E. N., ot al., British fournal of Surgery, 1974, 61, 319.

${ }^{8}$ Shapiro, S., Strax, P., and Venet, L., Fournal of the American Medical Association, 1971, 215, 1777.

${ }^{9}$ MacMahon, B., Cole, P., and Brown, J., fournal of the National Cancer Institute, 1973, 50, 21.

10 Bulbrook, R. D., and Hayward, J. L., Lancet, 1967, 1, 519.

\title{
Alternative Means of Access to Circulation for Chronic Haemodialysis
}

\author{
E. M. GORDON
}

British Medical fournal, 1975, 3, 358-359

\section{Summary}

Various standard techniques of access to the circulation for haemodialysis are ideal for most patients. Another type of internal fistula of large vessels, between the saphenous vein and the femoral artery, has been found useful in patients whose peripheral vessels are unsuitable for the standard means of access.

Charing Cross Hospital Medical School, London W6 8RF

E. M. GORDON, F.R.C.S., Senior Surgical Registrar

\section{Introduction}

A reliable means of regular access to the circulation, which allows patients to be intermittently connected to a dialyser, has been important in the development of haemodialysis as a generally accepted treatment for end-stage renal failure.

External shunts are simple to insert, painless to use, and adequate for several weeks or even months but have several disadvantages: clotting, recurrent sepsis, limitation of the patient's activities, and the need for occasional revision. The internal arteriovenous fistula obviates most of these difficulties. For most patients on maintenance haemodialysis the cephalic vein/radial artery fistula ${ }^{1}$ is quite suitable, but there are problems in constructing these fistulae in some patients owing to previous 
thrombophlebitis associated with intravenous infusions or to ligation of the vein during a "cut-down," and not all the fistulae are satisfactory as the cephalic veins do not always become sufficiently dilated. The fistulae may also thrombose after temporary hypovolaemia or become infected or aneurysmal and require ligation.

Saphenous vein loops were introduced for such patients in $1969 .{ }^{2}$ In the standard technique a vein loop is fashioned in the forearm, ${ }^{2}$ but others have placed the vein as a loop in the thigh ${ }^{3}$ and as a straight graft in the arm..$^{4-6}$ Recently preserved and cadaveric veins and arteries have been used as grafts. ${ }^{7} 8$ Thrombosis has proved to be a problem with loop grafts in the forearm and thigh, even when care is taken to ensure that the curve of the graft is adequate. Some patients have difficulty in inserting needles into thigh loops, as the abdominal wall protrudes over the site when they bend forward.

Subcutaneous placement of the $\operatorname{radial}^{9}$ and superficial femoral arteries $^{10}$ has been used as an alternative means of access to the circulation, and a mandril-grown graft has become available. ${ }^{11}$ This paper describes a variation of the vein graft technique which we have found to be useful.

\section{Technique}

The operation is best performed under general anaesthesia the day before a dialysis so that the effects of anticoagulants may be minimal and the patient at his maximal volaemic state. The side of the procedure is chosen with regard to previous leg shunts, preference being given to the limb in which the distal portion of the saphenous vein has already been used. After skin preparation and towelling the leg is positioned with the hip and knee flexed, the limb being externally rotated. It is useful to place a sandbag under the opposite buttock.

A transverse or longitudinal incision over the saphenofemoral junction is made and the vein isolated (see fig.). Tributaries are tied off with $2 / 0$ or $4 / 0$ silk but the saphenofemoral junction is not ligated.



The index finger is used to tunnel just deep to the saphenous vein. Gentle traction on the vein allows it to be palpated during this manoeuvre. Tributaries are tied and divided until the vein lies free. When the dissection has been carried as far as the finger can reach, a new transverse incision is made distally over the course of the vein. Aided by narrow retractors tunnelling is carried proximally and distally to free the vein. This is repeated until the level of the knee joint is reached, the last incision being longitudinal and deepened to expose the popliteal artery, round which slings are placed. The saphenous vein is divided distally and withdrawn to the groin incision where a bull-dog clamp is placed across the saphenofemoral junction. A soft catheter is inserted and the vein filled with heparinized Hartmann's solution. By pulsing the infusion all remaining leaks are found and ligated or sutured with 5-0 Tevdek and the vein kept in a distended state. The vein is rerouted subcutaneously, care being taken to avoid twisting, and anastomosed to the popliteal artery end to side via a longitudinal arteriotomy. The clamps are removed and the incisions closed. Paul's tubing drains are left in situ until 24 hours after dialysis. It is important to have sufficient length of vein so that it is not stretched over the fascia where it passes down to the popliteal fossa. The patient is gradually remobilized, and starts to bear weight one week later. The graft should not be used for four to six weeks after operation to permit the vein to become stable in its new tunnel, though earlier graft puncture (10 days) has been uneventful. The patient must be advised not to wear underwear which may cause constriction in the groin.

\section{Discussion}

We have performed this procedure in 10 patients and it has been entirely satisfactory up to 13 months after the operation and after 12 months' haemodialysis. There have been no cardiovascular complications during the follow-up. In another patient the saphenous vein was divided opposite the knee joint, and the distal end of the proximal segment was anastomosed to the popliteal artery. The vein was left in its normal position and tributaries were not ligated. Intense venospasm occurred during venepuncture, and 38 weeks later sympathetic denervation, ligation of thigh tributaries, and placement of the vein subcutaneously was performed. This produced no improvement and eventually thrombosis of the graft occurred. Such increased vascular tone is a normal phenomenon in leg veins in accordance with Toma's law. It seems that to mobilize the vein and place it superficially not only makes access easier but also is important in that the vein is thereby denervated.

In one case the graft was constructed to carry out haemodialysis against a low-magnesium bath content, a technique which is valuable in the treatment of malignant tumours. ${ }^{12}$ This patient had received intermittent intravenous cytotoxic therapy for many months and her peripheral veins were extensively sclerosed; the graft was valuable as a further site ot access to the circulatory system.

I thank Professor H. E. de Wardener and Dr. K. D. Bagshawe for allowing me to study patients under their care, Mr. Grant Williams for his help, and the medical illustration department of Charing Cross Hospital.

\section{References}

${ }^{1}$ Brescia, M. J., et al., New England fournal of Medicine, 1966, 275, 1089

2 May, J., et al., New England fournal of Medicine, 1969, 280, 770.

3 Perez-Alvarez, J. P., et al., Surgery, 1970, 67, 355.

4 Girardet, R. E., et al., Transactions of the American Society forArtificial Internal Organs, 1970, 16, 285.

${ }^{5}$ Mozes, M., et al., Surgery, 1970, 67, 452.

${ }^{6}$ Haimov, M., Singer, A., and Schupak, E., Surgery, 1971, 69, 884.

Zerbino, V. R., and Tice, D. A., Nephron, 1973, 10, 61.

8 Abu-dalu, J., et al., Archives of Surgery, 1972, 105, 798.

Capodicasa, G., Perna, N., and Giordano, C., Proceedings of the European Dialysis and Transplant Association, 1971, 8, 517.

${ }^{10}$ Brittinger, W. D., et al., Proceedings of the European Dialysis and Transplant Association, 1970, 7, 408.

11 Beemer, R. K., and Hayes, J. F., Transactions of the American Society for 2 Parsons, F. M., et al., Lancet, 1974, 1, 243 